\title{
Studying international doctoral researchers: nexus analysis as a mode of inquiry
}

\author{
Melina Aarnikoivu
}

\begin{abstract}
In this paper I argue how nexus analysis (Scollon \& Scollon, 2004), as a holistic, qualitative mode of inquiry, can offer a fruitful activist research approach to study international doctoral researchers. To do this, I will introduce and explain the core concepts of nexus analysis and afterwards empirically demonstrate how nexus analysis can be done in practice by presenting a case study on international doctoral researchers in a particular nexus-at a Finnish university. The overall aim of this paper is to present nexus analysis as a viable alternative for those higher education researchers who want to study communication, interaction, and language-related challenges of international doctoral researchers from a bottom-up perspective and, in this way, potentially even challenge the existing decision-making practices.
\end{abstract}

Keywords: doctoral education, qualitative methodologies, mediated social action, nexus analysis

Received 26 April 2020; revised version received 29 November 2020; accepted 1 December 2020. Corresponding author: Melina Aarnikoivu, University of Jyväskylä, Finland(melina.aarnikoivu@gmail.com).

\section{Introduction: what is nexus analysis?}

\begin{abstract}
Whatever issue you study, you will become deeply involved with it. The first place to look for that issue is in your own life, your own actions, and your own value system. What do you wish somebody would do something about? What do you think about to be changed in the world in which you regularly live? (Scollon \& Scollon, 2004, p. 154).
\end{abstract}

In 2015 I embarked on an ambitious personal journey with the above idea in my mind as a starting point. I had decided to start doing doctoral studies — on doctoral studies. This resulted in four sub-studies, which all focused on mediated social action (Scollon \& Scollon, 2004) that is involved in doing a doctorate. I conducted these interconnected studies by using nexus analysis (Scollon \& Scollon, 2004) as a mode of inquiry. Nexus analysis focuses on action, and allows the researcher to 
examine the linkages and relationships between different types of semiotic resources and social issues (see also Blommaert, 2010; Hult, 2015). It is built on the foundations of mediated discourse analysis (MDA), which specifically focuses on social action: 'any action taken by an individual with reference to a social network' (Scollon \& Scollon, 2004, p. 11).

Due to its developers'-Ron Scollon and Suzie Wong Scollon'sbackground in intercultural communication and discourse analysis, nexus analysis has previously mostly been used by scholars in applied language studies and communication studies (see, e.g., Hult, 2010; Jocuns, 2018; Tapio, 2013). While nexus analysis has also been used by some scholars in higher education contexts (see, e.g., Aarnikoivu et al., 2019; Hult, 2015; Scollon \& Scollon, 2004), it has mostly been ignored by researchers studying international students (for an exception, see Gaisch, 2014). However, as it is difficult to find a study on international doctoral researchers that does not at least in some way address the topic of communication, interaction, or language, it is striking that nexus analysis or other approaches, methodologies, and theories borrowed from linguistics or applied language studies are mostly absent in this field of interest. However, as I will go on demonstrating, nexus analysis would be a highly suitable mode of inquiry for a variety of disciplines beyond applied language studies, as it does not specifically focus on language or language use but rather on mediated social action, such as doing doctoral studies.

In this methodologically-oriented paper, I argue why nexus analysis is a particularly compelling alternative for studying international doctoral researchers ${ }^{1}$, who typically are a very heterogenous group - something which is often ignored in the research literature (Choi, Nieminen, \& Townson, 2012; Fotovatian, 2012). A feature that many of them share, however, is that they often have to navigate different types of social settings by using a language that is not their native one (Campbell, 2015; Ku, et al., 2008; Zeivots, 2020). Several studies have shown that an unfamiliar linguistic or cultural environment leads to challenges with socialisation, for example (Anderson, 2017; Elliot, Reid, \& Baumfield, 2016a; Elliot et al., 2016b). Challenges of non-English speaking background (NESB) doctoral researchers who study in English-speaking countries are particularly wellreported (see, e.g., Campbell, 2015; Li 2016; Zeivots, 2020), although it is important to bear in mind that an international doctoral researcher can also be a native English speaker studying in a non-English speaking country (see, e.g,. Sakurai, Pyhältö, \& Lindblom-Ylänne, 2012).

To construct my argument, I will show how nexus analysis enables the analyst to combine different methodologies and methods of data generation and, in this way, to form and ask new type of questions to highlight issues which might not

\footnotetext{
${ }^{1}$ In this paper, I primarily use the term 'doctoral researcher', according to the arguments I make in my dissertation (Aarnikoivu, 2020a, Chapter 3.2.3). However, when discussing the relevant research literature and the empirical context of this paper, I also use the term 'doctoral student' or 'international student', as these terms are used in the previous literature and by the studied university.
} 
have been noticed before by the social actors of the studied nexus. I will also demonstrate how nexus analysis can provide a bottom-up approach to studying different groups, such as international doctoral researchers. To do this, I will first introduce the core concepts of nexus analysis, as well as its position among other activist research approaches. Afterwards, I will present how nexus analysis can be done in practice by presenting a small case study on international doctoral researchers in a particular nexus - in Finland. Finally, I will conclude the paper by discussing how nexus analysis can be used to address and ask critical questions regarding international doctoral researchers and, ultimately, to potentially challenge the existing decision-making practices at a specific department, faculty, or university.

\section{The core concepts of nexus analysis}

In terms of methods and methodologies, nexus analysis is a highly flexible mode of inquiry. Although it typically includes at least ethnography and (critical) discourse analysis, it does not have to be limited to them. Besides providing a multitude of methodological possibilities, nexus analysis also offers a range of theoretical concepts. The most crucial ones are social action and social practice: When a specific social action happens repeatedly, it becomes a social practice. Both of these occur within an intersection, or nexus, of

1. discourses in place (discourses which, in a specific moment, circulate a particular material place where the studied social action takes place);

2. interaction orders (all the possible social arrangements that are being used to create relationships in social interaction; see also Goffman, 1983). (Scollon \& Scollon, 2004);

3. historical bodies (roles that different people embody related to their own personal experience, including one's goals, motivations, and personal attributes).

These three key elements intersect within the nexus under study, such as doing doctoral studies. Examining these three units of analysis allows the researcher to explain complex social phenomena that result in patterned social practices (Norris \& Jones, 2005). The focus of research should be both on smaller and larger entities, as well as on their linkages. Most importantly, the researcher should not 'get stuck' on single observable moments or participants but instead widen their perspective before 'zooming back in' again (Hult, 2010; Pietikäinen et al., 2011; Scollon \& Scollon, 2004).

However, to identify the relevant moments or participants, the analysis begins with 'engaging the nexus of practice' (Scollon \& Scollon, 2004), the first of the three steps of nexus analysis-engaging, navigating, and changing the nexus of 
practice - which I will explain in detail next, one by one. These steps will also form the main body of this paper before the discussion and the conclusion. It is important to note already at this point, however, that it is the final stage - changing - that is the ultimate goal of doing nexus analysis, which makes nexus analysis an activist research approach. As there are other several such approaches available for researchers, such as action research (see e.g. Given, 2008; Greenwood \& Levin, 2007) and critical action research (see, e.g., Davis, 2008), I will not attempt to argue that nexus analysis would somehow be better than other approaches. Instead, it is one possible mode of inquiry among others. What makes it different from other activist research approaches, however, is its focus on the relationship between language and social action specifically. For this reason, it is a particularly intriguing mode of inquiry to study social actions where language plays such a prominent role, such as doing a doctorate as an international doctoral researcher.

\section{The first steps: engaging the nexus of practice}

To demonstrate the potential and analytical power of nexus analysis in higher education research, and research on international doctoral researchers in particular, I will present a small-scale nexus analysis that I conducted at a Finnish university as part of my dissertation (Aarnikoivu, 2020a). The dissertation itself is a largerscale nexus analysis on doctoral education. At the start of my fieldwork (which took place between 2015 and 2017), I was focusing on doctoral researchers and supervisors as the main social actors within the focal nexus. However, as I was interviewing and observing doctoral researchers in Finland and abroad ${ }^{2}$, I began noticing that the international doctoral researchers partially spoke about different issues than the participants who were doing their studies in their country of origin, in Finland. Because of this contrast, I decided to 'zoom in' to this topic and generate more data on international doctoral researchers in particular.

Choosing one's research topic and establishing one's position in the studied community are both part of engaging the nexus of practice. However, this stage also includes the recognition of the critical social actors, events, discourses, and objects that are relevant for the studied phenomenon. Next, I will discuss these critical social actors and discourses on a more general level with references to relevant research literature, and then in terms of the empirical context of this paper. This is an important step, as no social action happens in a vacuum but is always connected to wider discourses circulating in society (Scollon \& Scollon, 2004), which is also shown by the following body of literature.

\footnotetext{
${ }^{2}$ I generated the dissertation data in two different settings: At a Finnish university and at a Central European research institute, where doctoral researchers of different nationalities work physically but are affiliated with different universities around the world.
} 


\section{The heterogenous group of international doctoral researchers}

The definition of 'an international student' is somewhat fluid (Cree, 2012): While international students are often referred to as students who have moved to a foreign country to study for a fixed period of time (Elliot et al., 2016a), there are not many shared characteristics that apply to all international students, however. They all have their own historical bodies (Scollon \& Scollon, 2004); they come from various backgrounds and education systems, speaking multiple languages, having their own motivations, expectations, and fears regarding their studies abroad (Ku et al., 2008; Manathunga, 2014). Furthermore, especially for an international doctoral researcher, moving to another country is often for an open-ended period of time, or leads to processes of complex mobility even though the doctoral students may not realise it at the time of locating to a new country (Aarnikoivu, 2020b; Hoffman, 2009).

Although the heterogeneity of international students is acknowledged in research literature (Asmar, 2005), it is also often ignored (Choi et al., 2012; Fotovatian, 2012; Manathunga, 2014). Instead, international students are all too often regarded as a homogenous mass with deficiencies in their English skills or having passive learning styles (Choi et al., 2012; Ryan \& Carroll, 2005). At its worst, international students are seen as a group which is not interested in academic achievement but merely a residency of the target country (Fotovatian, 2012), when in reality their motivations to study abroad are varied: pursuing academic or professional growth, intellectual stimulation, economic benefits, enhanced social status, or greater political freedom or stability (e.g., Kim, Bankart, \& Isdell, 2011; Zhou, 2015), for example.

Thus, the only feature that all international students share is being from somewhere else. This causes them to be categorised differently for administration purposes ('local' vs 'international students') and to be subjected to fees which are often higher than those of local ones (Fotovatian, 2012). 'International student' as a label might also emphasise the social, cultural, and physical space between students, constructing two separate identity groups (ibid.). Benzie (2010) characterised the negative consequences of 'otherness' as 'the process by which the discourse of a particular group defines others in opposition to itself and tends to make value judgements based on stereotyped opinions about that group as a whole' (Benzie, 2010, p. 450). The concern for the lost voice and silencing has also been brought up by several others: In their article on international students' perceptions on studying in an unfamiliar linguistic and cultural environment, Ryan and Viete (2009) criticised the marginalising nature of the power relationships that are hidden in different types of interactions within institutions. According to them, suppressing the voice of international students can lead to 'an intense loss of self-esteem and identity' (Ryan \& Viete, 2009, p. 307). As Fotovatian (2012) also pointed out, this is particularly important when considering that identities are negotiated in language interactions (see also Miller, 2004; Tran, 2013), which international students often do in a language that is not their mother tongue. Finally, Manathunga (2014) has 
discussed power issues in the context of intercultural postgraduate supervision. She argued that existing guidebooks on intercultural supervision do not adequately take into account the social, cultural, historical, and geographical contexts that surround intercultural supervision. She also pointed out some of the problems in the discourses circulating postgraduate supervision, which seem to paint a somewhat tidy picture of supervision, leaving out the messiness of different cultures, identities, and histories coming together. In nexus analytical terms, these could be called 'ignored historical bodies' within the 'relevant discourses in place'.

Going back to Benzie (2010), the 'otherness' does not only include the issues of language and interaction, however. Higher education institutions are globalised and function as a stage for several different types of student interactions that also involve different cultures, questions of power, membership, and legitimacy (Fotovatian, 2012). Therefore, all contexts of interaction are also related to negotiations of language, power, and culture (Norton, 2006), thus making higher education institutions and the interactions happening within them a place where social capital (Bourdieu \& Wacquant, 1992) is negotiated. What is equally important, however, is the cultural capital (Bourdieu, 1986), entailing the embodied state (consciously acquired properties of the mind and the body), the objectified state (acquired objects such as art and books) and the institutionalised state (acquired educational qualifications). Both of these forms of capital, social and cultural, both connect people with each other and distinguish individuals from each other.

As this brief literature review on international students and doctoral researchers illustrates, there are complex power dynamics and patterns of interaction happening within higher education institutions, which have both direct and indirect consequences for international doctoral researchers, as they navigate within the institutions they are studying at. In nexus analytical terms, the perceptions and expectations regarding the interaction orders (how and to whom to communicate in a university and in which language) and discourses in place (what is considered important, or foregrounded, in a given situation and what is not) might be very different for those who have a different kind of historical body (personal goals and dreams, cultural, social, and geographical background) than those that are familiar with the environment. Next, I will discuss some potential consequences for such tension by presenting a small case study that I did at a Finnish university, to provide an empirical grounding for my main argument.

The empirical context: the evaluation of doctoral training ${ }^{3}$ at a Finnish university Before moving on to describe the case-study used in this paper, I want to clarify that, ideally, doing nexus analysis is a long-term project consisting of several

\footnotetext{
${ }^{3}$ Throughout this article, I use the phrase "doctoral training" instead of "doctoral education". While these two terms differ in their meaning in English, in Finnish there is only one word for training and education: "koulutus". The university under study has chosen to translate "tohtorikoulutus" (doctoral education) into "doctoral training" in its English documents and websites, which is why I use this term as well.
} 
smaller studies - something that the Scollons also did back in Alaska 40 years ago. Nevertheless, it is possible to utilise nexus analytical concepts and methods to examine a smaller event or action. Within the scope of a single article, this is what I have chosen to do. Moreover, it is also customary for a nexus analyst not to specify any research questions before the beginning of data generation. Going back to my earlier point about the Finnish-born and international doctoral researchers talking partly about different things, the only guiding question for me at the beginning of this particular study was: why is it so?

Based on my preliminary observations, an interesting event I decided to 'zoom in on' was the evaluation of doctoral training, which took place at the university in spring 2016. The evaluation was part of the implementation of the operational agenda for the university's strategy, initiated by the university's Science Council and the Graduate School Steering Board. The reasons why I considered this event so important were: First, its purpose was to make sure that the university graduate school operates according to the principles and recommendations set by the University Board and the Graduate School Steering Board and that the doctoral training at the university is organised accordingly (University of Jyväskylä, 2016). In other words, the importance of the evaluation on the institutional level was significant. Second, the evaluation aimed at 'recognising the strengths and development needs of doctoral training at the University, promoting the sharing of good practices, improving the quality of doctoral training, and increasing understanding of how doctoral training is implemented in different fields of science' (ibid., p. 1), bringing a very practical and useful dimension to the evaluation from an individual doctoral researcher's perspective. Finally, based on the results of the evaluation, a development plan was created to improve the university's doctoral training between 2016 and 2020. This meant that the evaluation process largely determined how doctoral training was going to be shaped in the next few years, not only affecting current doctoral researchers but also future ones. This development plan was also to be assessed towards the end of the abovementioned period, which further emphasises its importance to the university.

The evaluation process consisted of three phases: a) self-evaluation of doctoral schools, b) school-specific evaluation discussions, and c) discussion among all doctoral schools about the future. Participants of these phases included doctoral researchers, supervisors, and the management of doctoral schools and doctoral programmes. The evaluation documents include the final report (in Finnish only), its summary (in Finnish and English), as well as the self-evaluation reports. Additionally, an event called 'the Future of Doctoral Education' was organised for doctoral researchers and supervisors in May 2016, where the preliminary results were discussed. This event also formed the third phase of the evaluation. The data are summarised in Table 1: 


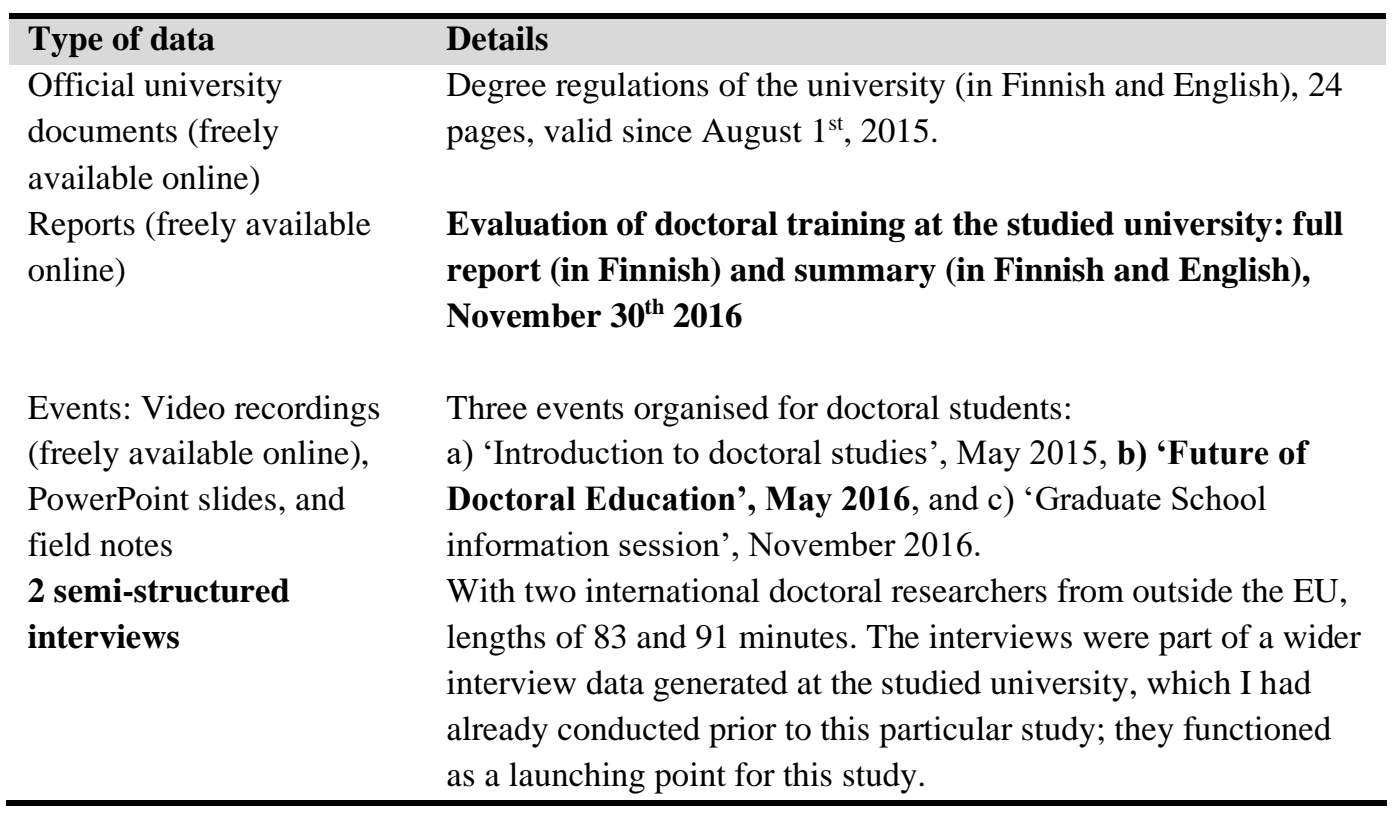

Table 1 . The data (the $1^{\text {st }}$ round of analysis).

It should be noted that while all of the data has to be analysed in the first round of analysis (by using content or discourse analysis, for example), not all of the generated data has to be included in the following rounds of analysis. For the purposes of this paper (the $2^{\text {nd }}$ round of analysis), I analysed the data marked in bold: the full report (in Finnish) and its English summary, Event B, and the two semi-structured interviews, which also prompted me to zoom into the topic of international doctoral researchers in the first place.

\section{Ethical considerations}

For the interviews I asked my participants to sign an informed consent form. I also had approval from the Head of Department where I generated the interview and other data for my dissertation. Most of the university-wide data was publicly available. To use the documents that were not public, I contacted the Graduate School Coordinator to ask for additional permission. After finishing my preliminary analysis, I also organised a meeting with the Coordinator to discuss the manuscript draft and analysis to confirm I had not misunderstood any aspect of the evaluation.

\section{The second stage: navigating the nexus of practice}

When navigating the nexus of practice, the analyst continues examining the discourses, social actors, actions, objects, and events which they first identified when engaging the nexus of practice. In practice, this stage entails a critical analysis of each of the three aspects that form mediated social action, which intersect and define a particular nexus, as explained previously: 1) discourses in place, 2) interaction orders, and 3) historical bodies. By examining these three aspects of 
social action, it is possible to 'make sense' of the issues which the analyst paid attention to at the beginning of their research process. To demonstrate how to navigate a specific nexus of practice, I will show how I navigated the topic of 'international doctoral researchers' during spring 2016.

\section{1) Discourses in place: what is talked about in relation to the university doctoral training?}

The first issue I focused on was the what: what was talked about during the evaluation and the specific event of 'Future of Doctoral Education', which took place in May 2016? The topics that the Graduate School Coordinator had chosen to be the PowerPoint slide headlines-something they had decided should be discussed during the event-were as follows: student recruitment; student guidance and supervision; supervision document and follow-up group; integration in the research community; career planning; degree requirements; doctoral degree funding; part-time students. These nine features can also be considered to be some (but not necessarily all) of the relevant-or foregrounded-discourses in place linked to the university's doctoral training: the discourses which, in a specific moment (on May 16 ${ }^{\text {th }}, 2016$ ), circulated and intersected within a specific material place (an auditorium at the university) where a specific social action (evaluation of the doctoral training) — or part of it — took place. The reason they are not necessarily all the discourses is because they are predetermined to a great extent; they are based on the evaluation which, at the time of the event, was almost completed. The evaluation and the topics that were selected (or de-selected) were chosen by a specific group responsible for implementing the evaluation. Moreover, the slides for the event were created by one person, the presenter, leaving very little room for other topics or discourses to be discussed or used in the event.

When taking a closer look at these discourses presented above, both doctoral students and part-time students as specific student groups are part of the relevant actors but international students are not. However, 'international students' were mentioned in the final report of the evaluation. In a later discussion with the Graduate School Coordinator, regarding the contents of this paper, they said that not talking separately about 'international students' was partly a conscious choice, to avoid separating them from the group of all doctoral researchers. This is in line with the critique by Fotovatian (2012), according to which the label of 'an international student' might emphasise the social, cultural, and physical space between international and local students and thus construct two separate identity groups. However, it is not in line with other parts of the evaluation which do talk about 'international doctoral students' or 'international applicants', illuminating that they are, in some way, a separate group that has to be considered. Neither is it in line with the reality in which the international doctoral researchers live and work, as will be seen in the further analysis. 


\section{2) Interaction order: who are discussing the university doctoral training?}

The next aspect of social action is the interaction order (all the possible social arrangements that we use to create relationships in social interaction) (Scollon \& Scollon, 2004, p. 13), about which I made a few key observations. Most of the analysed event consisted of presentations; one person at a time speaking to the audience. Occasionally some of the presenters engaged with the audience by reminding them that if they have any questions, they are free to ask them. After four speeches/presentations, however, the interaction order changed: the audience members were divided into smaller groups and asked to move into other rooms of the building to discuss two questions, assigned to them by the second speaker of the day. After the small group discussions, everyone returned to the main auditorium to share the results of their group discussions. This final part of the event was clearly more interactive. Although also initiated by the organisers, this change in the interaction order illustrates that they wanted and encouraged participation and dialogue; to hear what thoughts the preliminary results and questions following the presentation had awoken in the audience members.

It should also be noted that prior to the event, there were interviews between the evaluation organisers and doctoral researchers, supervisors, and faculty management (see Table 2 below). In other words, it was not the first time that those responsible for the evaluation wanted to reach out to other relevant social actors involved in the doctoral training. However, as with the discourses in places presented above, the social actors were also chosen by a specific group - those who implemented the evaluation. In the final report it is stated that during the evaluation, 60 doctoral students, 42 supervisors, and 22 people in doctoral school management positions were heard. The groups that participated in the evaluation in each of the three phases were the following:

\begin{tabular}{|c|c|}
\hline $\begin{array}{l}\text { Phase of the } \\
\text { evaluation }\end{array}$ & Participants of the phase \\
\hline $\begin{array}{l}\text { a) self-evaluation of } \\
\text { doctoral schools }\end{array}$ & $\begin{array}{l}\text { 'doctoral schools', freedom in choosing how to implement the self- } \\
\text { evaluation }\end{array}$ \\
\hline \multirow[t]{2}{*}{$\begin{array}{l}\text { b) school-specific } \\
\text { evaluation discussions }\end{array}$} & $\begin{array}{l}\text { - 'chairs' and 'secretary', } \\
\text { - 'doctoral students', 'English-speaking doctoral students', } \\
\text { 'supervisors', 'English-speaking supervisors', 'management of } \\
\text { doctoral schools and programmes' }\end{array}$ \\
\hline & $\begin{array}{l}\text { All participants are named in the final report; The participants of } \\
\text { each group were 'randomly chosen' by the doctoral school, however, } \\
\text { making sure that 'different types of student groups were represented } \\
\text { as well as possible'. }\end{array}$ \\
\hline $\begin{array}{l}\text { c) discussion between } \\
\text { doctoral schools about } \\
\text { the future }\end{array}$ & $\begin{array}{l}\text { Organised by the Graduate School Steering Board; All doctoral } \\
\text { students, supervisors, and management of doctoral schools were } \\
\text { invited to the event; 'The steering board plans the structure and }\end{array}$ \\
\hline
\end{tabular}


Table 2. Participants of the evaluation.

It was explicitly stated here that it is the Graduate School Steering Board (consisting of eight professors from different faculties) who planned the structure and themes of the discussion. This connects to the discourses in place, discussed above, as follows: Not only was it the what (to discuss in the evaluation/the studied event) that was decided by a smaller group of people but also the who (to ask about, to discuss with). While this is not a question whether this way of implementation is right or wrong, or good or bad, explicitly zooming in on these features of mediated social action provides the basis for the critical examination of international doctoral researchers and their studies in Finland. Specifically, it allows an analysis of what and who are not being talked about, and why. Finally, and most importantly, nexus analysis also allows the researcher to gauge the extent to which some of the relevant social actors possess an awareness of any of these issues, as well as any implications that might be caused because of the potential lack of awareness. This will be illustrated when examining the final part of social action, historical bodies, and how they relate to the first two parts; discourses in place and interaction order.

\section{3) Historical bodies: are the unique needs of international doctoral researchers recognised?}

As Norton (2001) has stated, in order to develop higher education pedagogies and studies within the institute, students' background and motivations have to be taken into account. By using the core concepts of nexus analysis, it is the historical body which refers to the different roles that people have related to their own personal experience, including one's goals, motivations, and personal attributes (Scollon \& Scollon, 2004, p. 13), such as one's social, cultural, historical, and geographical background (Manathunga, 2014), which were discussed previously in relation to international doctoral researchers and power.

In the context of this study, we therefore need to consider the historical bodies of those social actors who were involved in the evaluation process (see Table 2) but also those who are the interest of this study-international doctoral researchers doing their doctoral studies at the studied university, as well as their supervisors and colleagues. In the studied event, Future of Doctoral Education, several topics and groups of social actors were brought up by the presenters, as listed in an earlier section of the paper. A group that was almost completely missing from the discussion, however, were the international doctoral researchers: During the several hour-long event they were mentioned twice; when talking about the doctoral degree funding. One might argue that international doctoral researchers belong to the larger group of 'doctoral researchers' and there is no particular need to distinguish them from the main group. However, there are a number of issues that concern 'local' doctoral researchers but not international ones, and vice versa. 
These issues are caused mainly by laws and regulations set by higher-level actors such as the universities, funding agencies, and the state, all allowing or restricting access to the Finnish (or any) higher education system (see also Aarnikoivu, 2020b). For example, when mentioning international doctoral researchers in their presentation, the Graduate School Coordinator stated that the lack of funding is particularly problematic for international doctoral researchers because they might not understand that receiving a doctoral study position does not mean automatic funding from the university. They also pointed out that a sudden ending of one's funding might lead to 'a difficult situation'.

If looking at funding from an individual international doctoral researcher's point of view, this indeed is the case, as the following examples illustrate. The first is from an interview with one of the two international doctoral researchers participating in the wider dissertation study, who, at the time of the interview, had funding but was not sure if it would not be enough for the final stage of their studies:

\section{Excerpt 1 (emphasis added): So, my residency is tied to} the funding $[\ldots]$. As [a country] citizen it's not dire for me, it's not like I will be made to leave the country the moment my residency expires. However, it would be difficult for me to stay longer without funding. I have to find another permit and I would have to justify I have certain amount of money or I could just hang around, about three months and trying to figure things out. I don't think [that] it wouldn't be the case of 'you're gonna be deported from the country' but it would make things very difficult if I wasn't near completing and have more funding. [...] And I guess the thing is the summary part and the actual defence, it takes time to wait for the reviews to come back and to plan the actual defence as in getting the opponent and the timing and so on, for example I know someone who's waited over six months for their reviews to come which is not policy. So for them, cause they're Finnish it wasn't like having to worry about residency and visas and so but still there's this feeling of, things stuck and not knowing what to do.

Even if this participant did their everything to secure the funding for the rest of their studies, in theory it is possible that, in case they do not get funding, they would have to return to their country of origin and possibly quit their studies, which would be an enormous waste of resources; their own and the university's.

In their nexus analysis of the events involving their own experiences of pioneering computer-mediated communication in Alaska in the late 1970s and early 
1980s, the Scollons (2004) discussed the topic of gatekeeping. The Scollons hoped that their studies could provide help with developing strategies for dealing with potential structural barriers restricting educational equity within the university system. As they pointed out, universities (as bureaucratic and technological institutions) control the flow of people into the universities as well as through them (Scollon \& Scollon, 2004, p. 109). For instance, to become a doctoral researcher and to acquire a doctoral degree, there are several smaller gates, as well as gatekeepers: the university (who accepts doctoral researchers, organises the studies in the way they desire, and finally grants the degree), supervisors (who advise doctoral researchers on their doctoral path as a whole), the funders (the university or a foundation who enable doctoral students to finance their studies), and journal reviewers or thesis pre-examiners (who evaluate whether the work submitted by doctoral researchers is good enough in terms of existing standards). For international doctoral researchers, however, there is one additional gatekeeper, namely the state, which was neither mentioned, nor seen, except in the interview data-but purposefully and/or inadvertently excluded within the discourses in place and the interaction order. While for a Finnish-born doctoral researcher a closed funding gate means they either have to continue their research work for free or to find another job while looking for another source for funding, for an international doctoral researcher it means not only that they have to interrupt or possibly give up their ongoing work but also potentially leave the country (on mobility and residency issues of early-career scholars, see also Guth, 2008; Roksa et al., 2018).

While the second interviewed doctoral researcher was not equally worried about their funding, they expressed their will to stay and work in Finland after completing their doctorate but were uncertain if they could succeed in this:
Excerpt 2 (emphasis added): After PhD I'd like to continue working in academia, to be a researcher but now it is quite tough. I don't know if I'll be able to continue because I don't know whether I can have a chance to have a post-doc position... I like living here, this is not the first country that I've moved to, I've been living in different countries but I like Finnish people, I like the Finnish culture, I'd like to stay here for the rest of my life and to work in academia but I don't know if I can succeed or not.

This kind of complex mobility pattern is connected to Hoffman's (2009) critique on the definition of an international student and them changing countries for a fixed period of time. Instead, according to Hoffman, relocating to a new country is often open-ended and can easily lead to complex mobilities (such as with this participant who had lived in several different countries), though they might not realise it at the time of relocating. This suggests that conventional and narrow definitions of international (doctoral) mobility might prevent us from actually understanding the 
types of challenges missed by the actors driving this process. Although mobility patterns might be simple for some, that is not the case for everyone. This type of rethinking, in turn, encourages us to create a set of new questions related to doctoral education. These questions will be presented in the next section when discussing the final stage of nexus analysis, changing the nexus of practice.

\section{The final stage: changing the nexus of practice}

The final stage of the multi-level analysis process is changing the nexus of practice, which is also the ultimate goal of nexus analysis. Scollon and Scollon (2004) also call the stage 'an intervention' without a positivist solution: the purpose of doing nexus analysis is not to answer a specific set of ready-made research questions, or to re-examine established topics, but rather forming and asking new and better questions within nexuses that are not recognised as such, especially by the participants identified within a specific nexus. In this way, 'the results' of a nexus analysis do not consist of answers, but new questions asked by the analyst, and actions initiated by them.

Coincidentally, the idea of change was also communicated by an audience member in the event analysed above. During the final discussion, they asked how the results of the evaluation were going to affect the discussed issues in the future. They also wondered why they had a feeling that the university was asking the same things over and over again, evaluation after evaluation. Although perhaps not realised by the organisers of the event, or even by the person who asked the question, this point was extremely important. It highlights the same key issue discussed in the analysis presented above; the issue of power and gatekeeping:

- Who (interaction order) gets to decide what (discourses in place) is being evaluated or discussed in relation to doctoral education or training - and international doctoral researchers in particular-at universities? Why them?

- How are all these decided, and how do the decisions affect the topic that is being discussed?

Both the ones who implement such evaluations and the doctoral researchers these evaluations affect share the same goals-mapping out the current state and challenges of doctoral education and developing and improving its different aspects. Because of this it is crucial to ask better questions, based on an evolving understanding, rather than the questions that have been asked several times before. In this way, we might not only proceed with the study of international doctoral researchers but to highlight different issues in decision-making and power relations.

In addition to forming and asking new questions, the analyst also has an opportunity to affect the studied nexus with their own actions, as they are heavily involved in the action. Since completing the data generation in 2017, I have actively 
sought to participate in several developmental activities regarding (international) doctoral researchers where I have shared the results of this analysis:

- Presenting at a doctoral seminar of my department in November 2018 and again in September 2020.

- Having a discussion with the pedagogical leader of the department in September 2020.

- Participating in a meeting with two faculty representatives in November 2020, as well as taking part in a follow-up meeting with other doctoral researchers of my department. A set of developmental suggestions for the department and the faculty are currently being drafted.

Although most of the suggestions are targeted at the department where I generated the majority of the university data, I have also now been invited to a universitylevel meeting, which takes place in January 2021. In this meeting, I will be presenting the results of this and other studies included in my dissertation. Finally, I am now developing my future research agenda based on the work I started with the analysis presented in this paper. It is exactly because of nexus analysis and the tools it has provided me that I have been able to do all that as an early-career researcher. This also illustrates the power of nexus analysis as an excellent 'bottomup' research approach.

\section{Discussion}

Splitting the evaluation process analysed above into three intersecting aspects of social action (discourses in place, interaction orders, and historical bodies), it is possible to shed light on the complexity of some of the mechanisms that are affecting international doctoral researchers' lives: Coming from a different linguistic, cultural, or educational background than many of their doctoral researcher peers, international doctoral researchers might have less control and options to participate or voice their opinions if invited to do so. Instead, opinions can be more easily voiced by those who are familiar with 'the system', and decisions are made by those with power: doctoral schools, chairs, and management. They decide whom to ask, what to ask from them, and how much weight is put on the answers.

As I discussed previously, it is not a question of whether implementing the evaluation like this was a good or a bad idea. It is also difficult-and somewhat pointless - to assess, whether the evaluation could have been carried out any better, given the resources allocated to it. What can be concluded, however, is that a seemingly 'straightforward' or 'self-evident' process, such as an evaluation of doctoral training, which is 'business-as-usual' for most of the social actors involved in it, is anything but to those who are affected by the outcomes - the individual 
doctoral researchers, especially if their residence permit is about to run out and they are forced to leave the country before they can defend their thesis. For this reason, the results of this study can help in ensuring that all relevant social actors and their historical bodies are taken into account when assessing and developing doctoral education at a university level but also on a faculty and departmental level.

Going back to the heterogeneity and the research literature I cited previously in this paper, we cannot consider international doctoral researchers as being located merely in a certain space or time (Pennycook, 2005; see also Aarnikoivu, 2020b). Instead, they should be viewed as participants in a wider set of transcultural practices. This, according to Pennycook (2005), calls for a 'pedagogy of flow', as well as the need to create space for voices that have so far been unheard. He names this as being one of the greatest challenges of internationalising doctoral education. Considering that the internationalisation discourse is very much foregrounded and promoted in universities around the world, universities cannot afford to neglect international doctoral researchers-or international faculty in general-when carrying out different types of evaluation, development, or decision-making processes. If one talks the talk, one also has to walk the walk. This is especially important now after the tumultuous year of COVID-19, which has had a significant impact on international student flows.

Based on these earlier suggestions and to answer to this challenge, we should also consider and rethink the methodological options available to us researchers. While the strict word limits of journals might often set constraints for the researchers to explain their methodological choices thoroughly, the importance of choosing a particular methodology should not be ignored (see Jonker \& Pennink, 2009; Oliver, 2016; Opoku et al., 2016). Methodological choices and justifications are connected to how or who we are as researchers. As C. Wright Mills writes in his ground-breaking work on sociological imagination,

...you must learn to use your life experience in your
intellectual work: continually to examine and interpret it.
In this sense craftsmanship in every intellectual product
upon which you may work. To say that you can 'have
experience' means, for one thing, that your past plays
into and affects your present, and that it defines your
capacity for future experience. (Mills, 1959, p. 196).

Following the ideas of Mills, as well as the empirical observations of this paper, it is possible to formulate two additional questions to the ones presented in the previous section:

- What enables or restricts higher education scholars exploring modes of inquiry that are not typical in their 'home' discipline or field? 
- Why have international doctoral researchers been studied in the ways they have and what has been missed - if anything?

In his last major study, Bourdieu (2004) asked the same thing: What is usually swept under the carpet, never discussed, and more or less continuously misrecognised? As Scollon and Scollon (2004) state, during their research work the analyst is engaging in the very same discourses that they are studying. This is particularly important in qualitative research: the research participants have a unique past, present, and future but so does the researcher. Fully accounting for this relationship is a key hallmark of qualitative inquiry. But is it accounted for most of the otherwise interesting literature focused on international doctoral researcher literature?

Luckily, some interesting experiments and collaborative efforts can be found in the literature on international doctoral researchers. Some of the most noteworthy ones include the work done by Elliot et al. (2016b) on the 'hidden curriculum' and Elliot et al. (2016a) on academic acculturation. Moreover, there have been several scholars who have focused on international doctoral researchers' 'communities of practice': As Cai et al. (2019) summed up, such communities can enhance international doctoral researchers' identity, scholarly growth, as well as their psychological well-being. Researchers who participate in such practices and projects, wanting to facilitate change in their respective communities, demonstrate the kind of methodological imagination (Fine, 2018) which, I argue, is needed to answer the questions I have formulated above.

\section{Conclusion}

In the preceding three-stage analysis I have shown how nexus analysis (Scollon \& Scollon, 2004) provides a fruitful holistic, qualitative mode of inquiry for studying international doctoral researchers. I have done this by first introducing the three core concepts of nexus analysis. Second, I have demonstrated how to conduct such analysis by going through the three stages of nexus analysis - engaging, navigating, and changing the nexus of practice. Finally, I have discussed how a critical examination of a versatile data set is able to reveal something of interest, which is not typically discussed in relation to the studied nexus of practice, especially from a bottom-up perspective.

To claim that nexus analysis is the only mode of inquiry that is able to address complex topics that do not have simple answers would obviously be very narrow-minded. There are other equally appealing activist approaches for interdisciplinary research which utilise multiple methods and methodologies and aim at change, as discussed earlier. The purpose of this paper is not to raise nexus analysis on a special pedestal but rather introduce it to higher education scholars 
who may not have heard of it before, or if they have, might not have been courageous enough to explore it further.

Such an exploration would be important, however. As Wilkins (1999) states, applied language studies, as a field, is specifically 'concerned with increasing understanding of the role of language in human affairs and thereby with providing the knowledge necessary for those who are responsible for taking language-related decisions whether the need for these arises in the classroom, the workplace, the law court, or the laboratory' (p. 7; on higher education and language policies more specifically, see Saarinen, 2017, 2020). Although those who study international doctoral researchers or those who make decisions regarding them are not only addressing language-related challenges or making language-related decisions, language-related approaches and viewpoints cannot be excluded from the range of expertise that is needed to address the challenges of the heterogenous group of international doctoral researchers.

Despite it being quite a challenging approach, especially for an early-stage researcher, nexus analysis allows a great deal of flexibility for the analyst. However, its main challenge is the change: It is often accidental and not always welcomed (Scollon \& Scollon, 2004). Most of all, it is usually very slow. This is why attempting to seek fundamental change by writing one article-or even one dissertation - is not realistic. However, with small (yet determined and consistent) individual actions, by developing a coherent, long-term scholarly agenda over time, as well as by collaborating interdisciplinarily with other researchers focused on similar topics, a gradual but slow change is possible.

\section{Acknowledgements}

I would like to thank Taina Saarinen, David Hoffman, Jelena Brankovic, and all the anonymous peer reviewers for reading this article and providing valuable comments at different stages of the writing process.

\section{Funding}

This study was part of a dissertation project which was funded by the Faculty of Humanities and Social Sciences (the University of Jyväskylä), the Emil Aaltonen Foundation, and the Ellen and Artturi Nyyssönen Foundation. 


\section{Author biography}

Melina Aarnikoivu is a postdoctoral researcher at the Finnish Institute for Educational Research, University of Jyväskylä (Finland). Her research interests include doctoral education, academic writing, and ethnographic research methodologies. Melina is also a Joint Lead Editor of the ECHER blog (echer.org). 


\section{References}

Aarnikoivu, M. (2020a). “The Best Drunk Decision of my Life.” A Nexus Analysis of Doctoral Education. Jyväskylä: JyU Dissertations 256.

Aarnikoivu, M. (2020b). The spatiotemporal dimension of doctoral education: A way forward. Studies in Higher Education, Online first. https://doi.org/10.1080/03075079.2020.1723530

Aarnikoivu, M., Korhonen, S., Habti, D., \& Hoffman, D. M. (2019). Explaining the difference between policy-based evidence and evidence-based policy: A nexus analysis approach to mobilities and migration. Journal of Finnish Studies, 22(1-2), 213-240.

Anderson, T. (2017). The doctoral gaze: Foreign PhD students' internal and external academic discourse socialization. Linguistics and Education, 37, 110. https://doi.org/10.1016/j.linged.2016.12.001

Asmar, C. (2005). Internationalising students: Reassessing diasporic and local student difference. Studies in Higher Education, 30(3), 291-309. https://doi.org/10.1080/03075070500095713

Benzie, H. J. (2010). Graduating as a 'native speaker': International students and English language proficiency in higher education. Higher Education $\begin{array}{llll}\text { Research \& Development, 29(4), 447-459. } & \text {. }\end{array}$ https://doi.org/10.1080/07294361003598824

Blommaert, J. (2010). The sociolinguistics of globalization. Cambridge University Press. http://hdl.handle.net/1854/LU-8514822

Bourdieu, P. (1986). The forms of capital. In J. Richardson (Ed.), Handbook of Theory and Research for the Sociology of Education, 241-58. http://www.socialcapitalgateway.org/content/paper/bourdieu-p-1986-formscapital-richardson-j-handbook-theory-and-research-sociology-educ

Bourdieu, P. (2004). Science of Science and Reflexivity. Chicago: University of Chicago Press.

Bourdieu, P., \& Wacquant, L. J. D. (1992). An Invitation to Reflexive Sociology (1st edition). Chicago: University of Chicago Press.

Cai, L., Elliot, D. L., He, R., Liu, J., Makara, K. A., Pacheco, M., Shih, H.-Y., Wang, W., \& Zhang, J. (2019). A conceptual enquiry into communities of practice as praxis in international doctoral education. Journal of Praxis in Higher Education, 1(1), 11-36.

Campbell, T. (2015). A phenomenological study on international doctoral students' acculturation experiences at a U.S. university. Journal of International Students, 5(3), 285-299.

Choi, S. H.-J., Nieminen, T. A., \& Townson, P. (2012). Factors influencing international $\mathrm{PhD}$ students to study physics in Australia. Innovations in Education and Teaching International, 49(3), 309-318. https://doi.org/10.1080/14703297.2012.703017 
Cree, V. E. (2012). 'I'd like to call you my mother.' Reflections on supervising international $\mathrm{PhD}$ students in social work. Social Work Education, 31(4), 451-464. https://doi.org/10.1080/02615479.2011.562287

Davis, C. S. (2008). Critical action research. In L. Given (Ed.), The SAGE Encyclopedia of Qualitative Research Methods, 140-142. SAGE Publications.

Elliot, D. L., Baumfield, V., Reid, K., \& Makara, K. A. (2016b). Hidden treasure: Successful international doctoral students who found and harnessed the hidden curriculum. Oxford Review of Education, 42(6), 733-748. https://doi.org/10.1080/03054985.2016.1229664

Elliot, D. L., Reid, K., \& Baumfield, V. (2016a). Beyond the amusement, puzzlement and challenges: An enquiry into international students' academic acculturation. Studies in Higher Education, 41(12), 2198-2217. https://doi.org/10.1080/03075079.2015.1029903

Fine, M. (2018). Just Research in Contentious Times: Widening the Methodological Imagination. New York, NY: Teachers College Press.

Fotovatian, S. (2012). Three constructs of institutional identity among international doctoral students in Australia. Teaching in Higher Education, 17(5), 577-588. https://doi.org/10.1080/13562517.2012.658557

Gaisch, M. (2014). Affordances for teaching in an international classroom: A constructivist grounded theory. University of Vienna.

Given, L. M. (2008). Action Research. In The SAGE encyclopedia of qualitative research methods, 5-7. SAGE Publications.

Goffman, E. (1983). The interaction order: American Sociological Association, 1982 Presidential Address. American Sociological Review, 48(1), 1. https://doi.org/10.2307/2095141

Greenwood, D. J., \& Levin, M. (2007). Introduction to action research: Social research for social change (2nd ed). SAGE Publications.

Guth, J. (2008). The opening of borders and scientific mobility: The impact of EU enlargement on the movement of early career scientists. Higher Education in Europe, 33(4), 395-410.

Hoffman, D. M. (2009). Changing academic mobility patterns and international migration: What will academic mobility mean in the 21 st century? Journal of Studies in International Education, 13(3), 347-364. https://doi.org/10.1177/1028315308321374

Hult, F. M. (2010). Analysis of language policy discourses across the scales of space and time. International Journal of the Sociology of Language, 2010(202). https://doi.org/10.1515/ijsl.2010.011

Hult, F. M. (2015). Making policy connections across scales using nexus analysis. In F. M. Hult \& D. C. Johnson (Eds.), Research Methods in Language Policy and Planning, 217-231. John Wiley \& Sons, Inc. https://doi.org/10.1002/9781118340349.ch19 
Jocuns, A. (2018). Examining traditional communicative practices in Gerai, Indonesia: A nexus analysis. Journal of Multicultural Discourses, 13(1), 3751. https://doi.org/10.1080/17447143.2018.1438441

Jonker, J., \& Pennink, B. P. (2009). The Essence of Research Methodology: A Concise Guide for Master and PhD Students in Management Science. Berlin / Heidelberg: Springer-Verlag. https://doi.org/10.1007/978-3-540-71659-4

Kim, D., Bankart, C. A. S., \& Isdell, L. (2011). International doctorates: Trends analysis on their decision to stay in US. Higher Education, 62(2), 141-161. https://doi.org/10.1007/s10734-010-9371-1

Ku, H.-Y., Lahman, M. K. E., Yeh, H.-T., \& Cheng, Y.-C. (2008). Into the academy: Preparing and mentoring international doctoral students. Educational Technology Research and Development, 56(3), 365-377. https://doi.org/10.1007/s11423-007-9083-0

Li, M. (2016). Developing skills and disposition for lifelong learning: Acculturative issues surrounding supervising international doctoral students in New Zealand universities. Journal of International Students, 6(3), 740-761

Manathunga, C. (2014). Intercultural Postgraduate Supervision: Reimagining time, place and knowledge. New York, NY: Routledge.

Miller, J. (2004). 10. Identity and language use: The politics of speaking ESL in schools. In A. Pavlenko \& A. Blackledge (Eds.), Negotiation of Identities in Multilingual Contexts, 290-315. Multilingual Matters. https://doi.org/10.21832/9781853596483-013

Mills, C. W. (1959). The sociological imagination. Oxford: Oxford University Press.

Norris, S., \& Jones, R. H. (2005). Discourse in Action: Introducing Mediated Discourse Analysis. Routledge.

Norton, B. (2001). Non-participation, imagined communities and the language classroom. In M. Breen (ed.), Learner contributions to language learning: New directions in research, 159-71. Essex, England: Pearson Education.

Norton, B. (2006). Identity as a sociocultural construct in second language education. In Cadman, K. \& O'Regan, K. (Eds.), TESOL in Context [Special Issue], 22-33.

Oliver, P. (2016). The Revolt of the Reviewers: Towards Fixing a Broken Publishing Process. The American Sociologist, 47(2/3), 344-355.

Opoku, A., Ahmed, V., Akotia, J., Ahmed, V., \& Akotia, J. (2016, March 10). Choosing an appropriate research methodology and method. In V. Ahmed, A. Opoku, and Z. Aziz (Eds.) Research Methodology in the Built Environment, 32-49. London: Routledge.

Pennycook, A. (2005). Teaching with the Flow: Fixity and fluidity in education. Asia Pacific Journal of Education, 25(1), 29-43. https://doi.org/10.1080/02188790500032491

Pietikäinen, S., Lane, P., Salo, H., \& Laihiala-Kankainen, S. (2011). Frozen actions in the Arctic linguistic landscape: A nexus analysis of language 
processes in visual space. International Journal of Multilingualism, 8(4), 277-298. https://doi.org/10.1080/14790718.2011.555553

Roksa, J., Jeong, S., Feldon, D., \& Maher, M. (2018). Socialization experiences and research productivity of Asians and Pacific Islanders: "Model minority" stereotype and domestic vs. international comparison. Research in the Sociology of Education. Online first, 155-179. https://doi.org/10.1108/S1479-353920180000020007

Ryan, J., \& Viete, R. (2009). Respectful interactions: Learning with international students in the English-speaking academy. Teaching in Higher Education, 14(3), 303-14. https://doi.org/10.1080/13562510902898866

Ryan, J. M., \& Carroll, J. (2005). 'Canaries in the coalmine': International students in Western universities. Teaching International Students. Improving Learning for All, 1-10.

Saarinen, T. (2017). Policy is what happens while you're busy doing something else: Introduction to special issue on "language" indexing higher education policy. Higher Education, 73(4), 553-660.

Saarinen, T. (2020). Higher Education, Language and New Nationalism in Finland. Recycled Histories. Cham, Switzerland: Palgrave Pivot.

Sakurai, Y., Pyhältö, K., \& Lindblom-Ylänne, S. (2012). Factors affecting international doctoral students' academic engagement, satisfaction with their studies, and dropping out. International Journal for Researcher Development, 3(2), 99-117 http://dx.doi.org/10.1108/17597511311316964

Scollon, R., \& Scollon, S. B. K. (2004). Nexus Analysis: Discourse and the Emerging Internet. London: Routledge.

Tapio, E. (2013). A nexus analysis of English in the everyday life of FinSL signers: A multimodal view on interaction. Jyväskylä: University of Jyväskylä Printing House.

Tran, L. (2013). Transformative learning and international students negotiating higher education. In S. Sovic \& M. Blythman (Eds.), International students negotiating higher education: critical perspectives, 124-141. London: Routledge.

University of Jyväskylä. (2016). Evaluation of doctoral training at the University of Jyväskylä - Summary of the final report. University of Jyväskylä. https://www.jyu.fi/fi/tutkimus/tohtorikoulutus/tohtorikoulutuksenarviointi/tohtorikoulutuksen-arvioinnin-loppuraportin-yhteenveto_en.pdf

Wilkins, D. A. (1999). Applied linguistics. In B. Spolsky (Ed.), Concise Encyclopedia of Educational Linguistics, 6--17. New York, NY: Elsevier.

Zeivots, S. (2020). Outsiderness and socialisation bump: first year perspectives of international university research students. Asia Pacific Journal of Education, Online first. https://doi.org/10.1080/02188791.2020.1779028

Zhou, J. (2015). International students' motivation to pursue and complete a Ph.D. in the U.S. Higher Education, 69(5), 719-733. https://doi.org/10.1007/s10734-014-9802-5 